\title{
Play, learn, explore: grasping complexity through gaming and photography
}

\author{
Patrick O. Waeberı, ", Arnaud De Gravellı, Lucienne \\ Wilmélv, v, vı, Claude Garcial, vıl
}

\author{
Correspondence: \\ Patrick O. Waeber \\ ETH Zurich, Ecosystems Management, Forest Management and \\ Development Group, \\ Universitätsstraße 16, 8092 Zurich, Switzerland. \\ Email: patrick.waeber@usys.ethz.ch
}

\begin{abstract}
"Science and art are only too often a superior kind of dope, possessing this advantage over booze and morphia: that they can be indulged in with a good conscience and with the conviction that, in the process of indulging, one is leading the 'higher life'."

--Aldous (Leonard) Huxley, Ends and Means (1937), 320. In Collected Essays (1959), 369--
\end{abstract}

\begin{abstract}
Increased demand for agricultural products, the aspirations of rural communities and a growing recognition of planetary boundaries outline the complex trade-offs resource users are facing on a daily basis. Management problems typically involve multiple stakeholders with diverse and often conflicting worldviews, needs and agendas, in an environment with growing uncertainty. How to improve the flow of information between decision makers? What future landscapes will best resolve the apparently conflicting demands? To address these questions, our methodology has been based on participatory modeling and 'ethnophotography in environmental science', a term we have coined to describe our use of photography to explore the perceptions of landscape by resource users. We apply these coupled methods in the social-ecological landscape of the Alaotra, Madagascar. Within the realms of the AlaReLa (Alaotra Resilience Landscape) project, we have developed conceptual models that link actors, resources, norms and institutions, ecological processes and social dynamics through participatory modeling workshops. These involved farmers, academics, conservationists and decision makers. Recognizing and understanding the multiple linkages and feedback loops between all of these components and processes is a crucial first step in the design of socially acceptable strategies. In this paper we highlight the interaction of participatory research and photography, to show how they exchange and nurture each other, and how this approach allows the evolution of a common understanding of a social-ecological system.
\end{abstract}

\section{RÉSUMÉ}

L'augmentation de la demande de produits agricoles, les aspirations des communautés rurales et la reconnaissance croissante d'une planète aux frontières limités mettent en exergue les compromis complexes auxquels les utilisateurs des ressources sont confrontés de manière quotidienne. Ces problèmes de gestion impliquent généralement de multiples parties prenantes ayant des visions du monde et des besoins variés et souvent conflictuels, dans un environnement où l'incertitude augmente. Comment peut-on améliorer le flux d'information entre les preneurs de décision ? Quels futures utilisations du territoire résoudront au mieux des demandes apparemment contradictoires ? Pour répondre à ces questions, notre méthodologie a été basée sur la modélisation participative et I'« ethnophotographie en sciences de l'environnement », terme que nous avons créé pour décrire notre utilisation de la photographie afin d'explorer les perceptions de leur environnement par les utilisateurs de ressources. Nous appliquons ces méthodes couplées dans le paysage socio-écologique de l'Alaotra, à Madagascar. Dans le cadre du projet AlaReLa (Alaotra Resilience Landscape), nous avons développé des modèles conceptuels qui relient les acteurs, les ressources, les normes et institutions, les processus écologiques et la dynamique sociale à travers des ateliers de modélisation participative. Les participants en étaient des agriculteurs, des universitaires, des conservationistes et des décideurs. Mettre en évidence et comprendre les liens multiples et les boucles de renforcement entre tous les composants et processus est une première étape cruciale dans la conception de stratégies socialement acceptables. Dans cet ar-

\footnotetext{
I ETH Zurich, Ecosystems Management, Forest Management and Development Group, Universitätsstraße 16, 8092 Zurich, Switzerland.

II Madagascar Wildlife Conservation, Lot 17420 bis Avaradrova Sud, 503 Ambatondrazaka, Madagascar. Ecopalimpsesto(Photo)Graphies, 76 rue du pla, 11510 Fitou, France.

Missouri Botanical Garden, Madagascar Research \& Conservation Program, 101 Antananarivo, Madagascar University of Antananarivo, School of Agronomy, Water and Forest Department, 101 Antananarivo, Madagascar. World Resources Institute, $10 \mathrm{G}$ Street, NE, Suite 800, Washington, DC 20002, USA.

UR Forêts et Société (F\&S), Département Environnements et Sociétés du CIRAD, Campus International de Baillarguet, 34398 Montpellier Cedex 5, France.

Citation Waeber, P. O., De Grave, A., Wilmé, L., Garcia, C. 2017. Play, learn, explore: grasping complexity through gaming and photography. Madagascar Conservation \& Development XX, XX: XX-XX. http://dx.doi.org.10.4314/mcd.wetlands.1 // Early View
} 
ticle, nous soulignons l'interaction entre la recherche participative et la photographie, afin de montrer comment elles échangent et se nourrissent l'une de l'autre, et comment cette approche permet une évolution vers une compréhension commune d'un système socio-écologique.

\section{STAGING PARTICIPATORY RESEARCH}

Protected areas globally cover $15.4 \%$ of the 13 billion hectares that form Earth's land mass (Deguignet et al. 2014). It does not seem enough to curb the loss of biodiversity and the decline of wild populations documented world over (Worm et al. 2006, Butchart et al. 2010, Cardinale et al. 2012). Yet, it is almost the same amount that is devoted to crop production-arable land and permanent crops cover some 1.6 billion hectares according to Guillou and Matheron (2014). It seems unlikely that we will be able to establish new parks to reduce the environmental damage man is causing to the biosphere. In this context, a crucial question is also related to how to deal with human dominated landscapes. Pett et al. (2016:2) note that "[policy- and decision makers] have to deliver and trade-off between multiple biodiversity, individual, and societal benefits (...), environmental interventions that deliver mutually reinforcing outcomes for both biodiversity conservation and people are highly desirable." We are confronted with fundamental questions: How do people cope with conflicting agendas, power imbalances, uncertainty and the unknown when managing natural resources? How do they resolve the trade-offs between satisfying their needs and maintaining the ecosystems they live in and depend on? Orstom (2009) speaks of increased complexity of a social-ecological system (SES) when its subsystems such as Resource System (e.g., wetlands, forests), the Resource Units (e.g., fish stock, marshes, protected area) or its Resource Users (e.g., fishers, park rangers) and respective Governance systems (e.g., Ministry of Agriculture, or Ministry of Fisheries) are interacting with each other and feeding back at either the SES or lower subsystemic levels. The emergence of transdisciplinarity approaches in environmental and sustainability sciences represent ideal platforms to accommodate the interactions and exchanges between and amongst different types of actors to address aforementioned questions (Max-Neef 2005, Lang et al. 2012); Kates et al. (2001:641) suggests that "participatory procedures involving scientists, stakeholders, advocates, active citizens, and users of knowledge are critically needed" when dealing within complex and complicated realms such as natural resources management systems.

In this article we provide insights on how a participatory modeling approach based on the ComMod methodology (Etienne et al. 2014) and art, in particular photography, are complementing and nurturing each other to gain increased understanding of a complex landscape as that of the Alaotra, where agricultural needs and conservation biodiversity interests compete over space (e.g., Waeber et al. 2017a). This contribution is placed in the AlaReLa project, which is a "rud" research for development project supported by the Swiss Programme for Research on Global Issues for Development.

\section{PRESENTING ACTORS AND PLAYERS}

Madagascar, a global biodiversity hotspot (Ganzhorn et al. 2001), hosts a vast variety of ecosystems from very dry to very wet forests and open landscapes (Waeber et al. 2015); this has created a unique assemblage of flora and fauna, with some of the species being found only in certain areas of this big island (Wilmé et al.
2006, 2012), and many being threatened or on the brink of extinction. In the north-eastern part of the island, Lake Alaotra was once the biggest inland fish supplier. It is referred to as the leading rice granary of Madagascar. Its marshes also provide habitat to the Alaotra Gentle Lemur (Hapalemur alaotrensis), the only lemur species to live constantly on water (Waeber et al. 2017b). In 2003, Lake Alaotra was the third wetland in Madagascar to be designated as a Ramsar site; in 2007, the Malagasy government added the Alaotra as a new protected area in the context of the Durban vision; in June 2015, the Alaotra has been inscribed as a permanent Protected Area (Waeber et al. 2017a). Despite these formal labels, marshes are burnt to expand rice fields and to ease access to fish ponds (Ralainasolo et al. 2006, Copsey et al. 2009a, b, Ratsimbazafy et al. 2013), thereby reducing the size of lemur habitat.

While bushmeat hunting was in decline in the early 2000 s (Ralainasolo 2004), it recently sprang back, probably due to the political instability and the lack of governance and law enforcement during the High Authority of Transition (HAT) period (2009-2013) (Randrianja 2012). Reduced livelihood options forced many residents into the marshes in search of alternative sources of proteins, mainly birds and mammals. During our focus group meetings and participatory game workshops (cf. Reibelt et al. 2017), fishers were also raising the concern that more and more people are entering marshes in desperate search for fish, and they catch them by any means possible. As a result, the once thriving fisheries of Lake Alaotra are now imperiled. Overfishing, like bushmeat hunting or logging, are classic examples of a conservation crisis during times of political turmoil (e.g., Golden 2009, Innes 2010, Randriamalala and Liu 2010, Jenkins et al. 2011). Desperate people take whatever action is needed to make ends meet. Many environmental challenges, however, are "remotely controlled" (cf. Waeber and Wilmé 2013).

The Alaotra has many different actors (Figure 1) posing increased challenges to the ones responsible for the management of the wetlands. The biggest group of actors are the farmers and fishers. Their actions change the landscape; they directly depend on its natural resources to satisfy their needs. But they are not alone. In the supporting role, middlemen and consumers are linked to the direct actors by a web of exchanges and reciprocities, making the decisions of the latter the logical choice. And then there is the second type of actors: the policy makers, regulators, responsible for the norms and policies that shape and enable decision making by the main actors. These are often people that do not derive their subsistence from the land and its resources. The large number of poor people are prone to take chances in the form of illegal land conversions, hunting, mining, and logging. This brings into play a third type of actors: those who have the power to abuse the situation of the main actors and know how to manipulate and interfere with the supporting roles and the regulators. They are powerful and 'above the law'. No strategy for conservation that does not take them into consideration will work. Two changes can reduce the likelihood of these actors' interference and limit their power: the first, a reduced exposure of the direct actors (farmers, fishers), achieved by improving their economic situation and thus reducing their vulnerability to change. The second, better governance through increased accountability of the regulators. Creating conditions that can increase transparency in natural resources management is a crucial step towards any tangible solution (Grindle 2004, but see also Kolstad and Wiig 2009). 


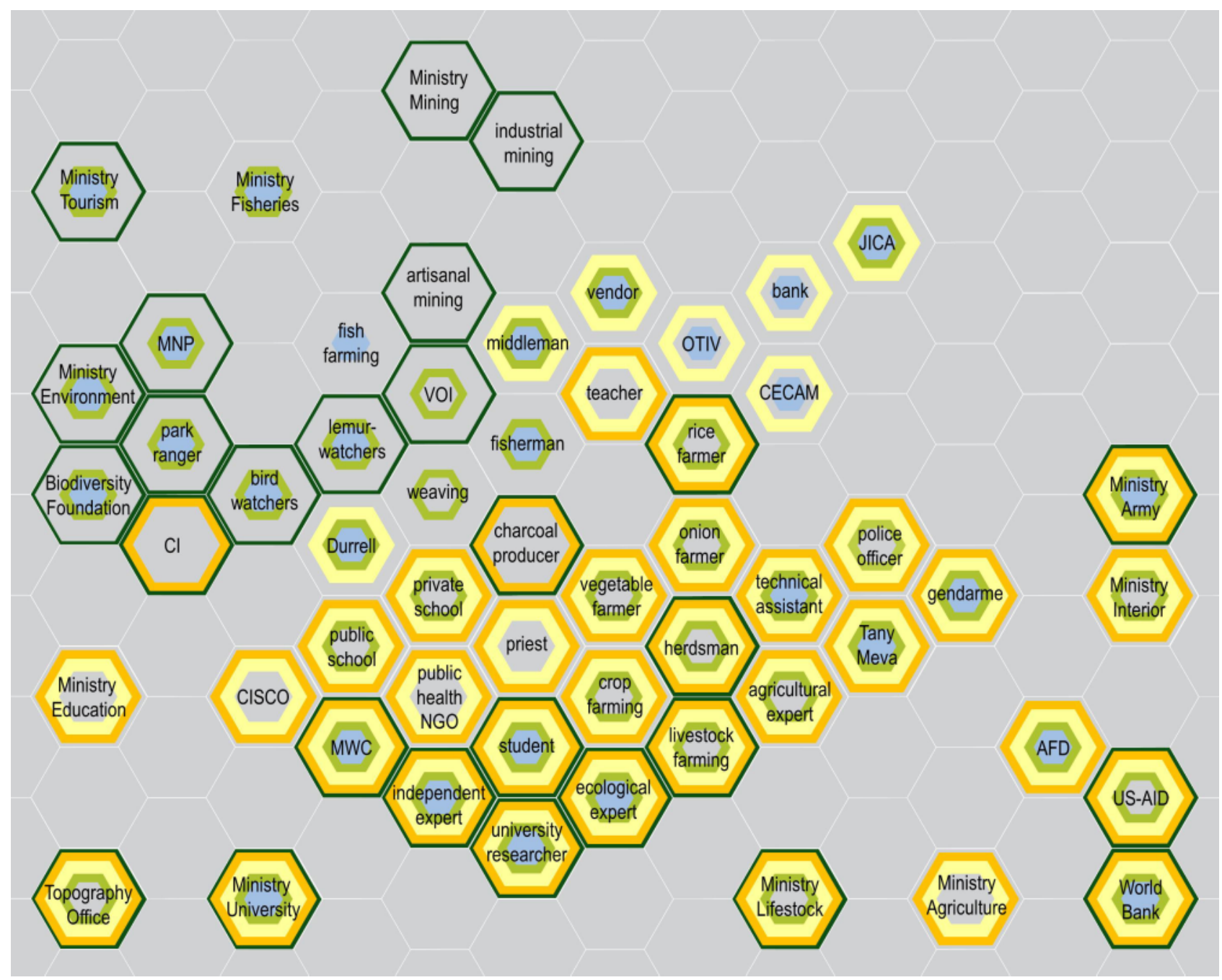

Figure 1. Stakeholder map developed in the course of the AlaReLa project, illustrating the social-ecological networks of the Alaotra landscape. An actor is represented by a hexagon, and is active in one to five zones of the landscape; lake (blue), wetlands (light green), agricultural zone (yellow), grasslands (orange), and forests (dark green). The position of an actor shows its connections with others as well as the spatial scale of activity; the closer an actor is to the center, the smaller the spatial range and bigger the dependency on local resources (village level). AFD = French Development Agency; CECAM = microcredit institution; $\mathrm{Cl}=\mathrm{Conservation}$ International; $\mathrm{CISCO}=$ regional school authorities; JICA = Japan International Cooperation Agency; MNP = Madagascar National Parks; MWC = Madagascar Wildlife Conservation; OTIV = microcredit institution; $\mathrm{VOI}=$ local association responsible for management of natural resources at community level.

Through our serious games (haptic models), people can explore the complexity of the issues at stake, shatter their illusion of understanding, and create space for communication and negotiation (e.g., García-Barrios et al. 2015, Le Page et al. 2016, Garcia et al. 2016). The models are first developed through workshops where local empirical knowledge meets scientific knowledge on an equal basis. Here, farmers and fishers explained to the research team what matters to them when deciding to manage resources (Reibelt et al.2017; Figure 2). We then translate these early mind-maps (Figure 2) into board games, where actors become players, resources are tokens, norms and processes define the rules, and the landscape is the board. These games can be played by the main actors, by regulators, or by other actors. Throughout the learning process, we can refine our understanding, when the players propose fixes to the game, and we can use the game board to explore potential policy_or scenarios_and see how players devise new strategies to cope with them. Finally, the game session and the board can be used as metaphors to discuss about the real world (Figure 2).

\section{WHEN ORAL NARRATIVE MEETS VISUAL INTERPRET- ATION}

In Madagascar, social or collective memory (sensu Coser 1992) and oral tradition is still ubiquitous; this is evident also during scientific meetings, where every workshop starts with a kabary (lengthy discourse) in local dialect, and also closes with a traditional narrative given by a more elder and respected member of the community (Cole 1997). Thus, game playing allows the local actors, in our case fishers and farmers, to express themselves orally and thus contributing to a broader and deeper insight of the social-ecological system. A professional photographer (ADG) joined the research team, and like the researchers, spent extended periods of time in the Alaotra. Embedding what we dubbed 'ethno-photography in environmental sciences' (Box 1) in the research project, we seek to develop synergies between this artistic approach and the participatory action research described earlier. Researchers thereafter use the photography as a support to engage local stakeholders, discover new elements of the system, and bring research outcomes beyond the walls of academia (cf. Figure 2 for the interlinking of photography, mental models, and 


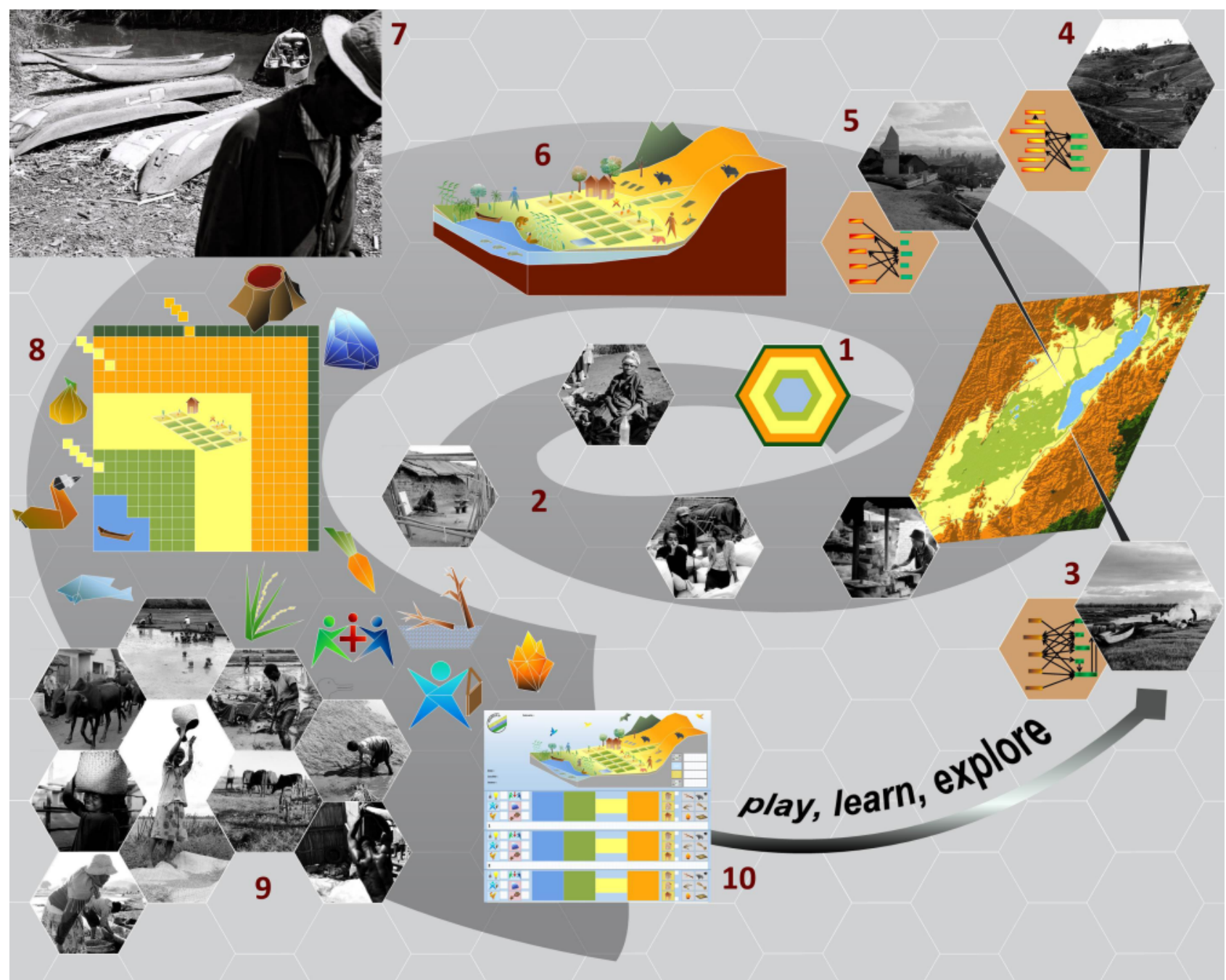

Figure 2. Transformative learning, i.e., the acquisition of knowledge and understanding through critical thinking (Mezirov 1997), with coupled approaches in an iterative process. [1] stakeholder mapping (cf. Figure 1); [2] black and white analog pictures describing the villagers' daily life; [3, 4, 5] social-ecological networks and mental models, as well as typical landscapes of three study sites mapped on a figure illustrating relief and land cover types, respectively in the Andreba region [3] along the lake border, the hilly north near Vohimarina [4], and the western plains near Anororo [5]; [6] stylized landscape with the lake (blue) and wetlands (light green) home to the narrow ranged endemic biodiversity, the agriculture zone (yellow), the hilly grasslands (orange) and remote rainforest (dark green); [7] a respected old man coming from the canoe port at dusk after a fishing journey; [8] board game representing the landscape, tokens and cards for the role-playing game where actors become players; [9] result of the iteration process in ethnophotography illustrating the farmers and fishermen working techniques; [10] game sheet filled by each participant during a game session and to be taken home to stimulate discussions in a household on the understanding of the Alaotra as an integrated landscape.

role playing games). The photographer used the participatory research project to develop narratives about timelines, roles and actors.

The modus operandi for the photography project has well identified steps matching the development of the participatory modeling process. In the diagnostic phase, the photographer joined researchers in their initial field work and brought a first harvest of pictures. We obtained three different batches of pictures: (i) a set of black and white analog pictures ('analogies') showing the life of villagers as seen through the photographer's eyes; (ii) a set of color digital pictures overlapping the first set but with less of an aesthetic parti-pris and documenting the work of the researchers; and (iii) a set of instant photographs using a Fuji Instax camera that were given directly to the people as the first step in sharing the project outcomes, in this case, their image, with them (Figure 3). Through photography we followed the different types of actors we had identified in the system, in their daily lives, and see if and how they interconnect, documenting their social-ecological networks (see also Figure 1) that are at the basis of knowledge production and collective actions in a landscape to document the different roles a person takes in the system and in the transdisciplinary research process (Opdam et al. 2013). We wanted to have portraits of them 'acting', e.g., 'a day in the life of a fisherman' for example, and of them 'playing their roles' in the role playing games we had co-designed with them (e.g., Reibelt et al. 2017). As a result, this started the second iteration of the project, the exploration phase, with the second field visit aiming at filling these gaps (Figure 4). Not only did participants take home the photographs, but the players also took home the game sheets. It is our assumption that, by combining the photographer's and the actors' views through this iteration, we can obtain a fuller representation of the social-ecological-economical system. The photographs and game sheets taken home will also allow the local participants to enrich further iterations with more details for a better understanding of the system (Figure 2). We expect surprises to emerge from these interactions between the villagers, the researchers and the photographer. In a longer project (e.g., longer than the three years of the AlaReLa project), we would continue doing iterations like 


\section{Box 1. Ethnophotography in environmental sciences.}

What: Ethnophotography helps to put faces behind the scientific findings. It provides communication alternatives in the realms of environmental sciences and related topics. The modus operandi is inspired by ethnography and includes long stays in the field, close collaboration with scientists, and participatory photography with local and regional stakeholders and thus differs from classic documentary photography. The outcomes encompass coherent series of images bridging the gap between science and art; photography in support of scientific results and science brought to the mainstream via photography. The photographer connects the scientists and the local stakeholders to lessen the 'white coat syndrome'. The photography is used alongside other forms of research and engagement-interviews, participant observation, participatory modeling via role-playing games - to foster transdisciplinarity. At the core, it uses photography as a medium to confront the perceptions of researchers and stakeholders. The participatory approach associates an unconditional positive attitude derived from the field of facilitation and observant participation. Coupled with the scientific project workshops of participatory modeling, the photographer documents the daily life and work of the inhabitants, the researchers in the field and their interactions with locals. He therefore integrates their visions and perceptions of the landscape, its resources and actors during the shooting process. This is done through discussions with the 'models' about the way they want to be portrayed during specific iteration workshops. Instant photography is also performed in order to get a quick feedback, but also to give back to the locals as well as using their image and knowledge (e.g., at conferences or in articles).

How: We created the concept of iteration workshops to converge to a set of shared visions. These iterations were done with the local people on-site and with all national and international stakeholders, building on iterations over iterations. During a first visit in each of the sites of the project, the photographer built a corpus of images with his personal view on the encountered situations and vision, biased with personal background and the limited time of this first stay. During further visits we organized the iteration workshops, showing the locals the first harvest of pictures and asking them to reflect on it in order to help portray them and their lives in a more accurate way. The basic question was: "this is what the photographer saw, what did he miss?" Therefore, and with the stakeholders' input, we entered a new phase of photography in which we built upon the visions previously missed to create a shared vision. The locals then act as 'fixers' but with their own agenda, which is the way they want to be represented. The resulting pictures were then used in exhibitions during scientific conferences to foster discussions and bring nonstereotyped visions from the fields but also in other non-scientific loci (art gallery, cultural centers) to give visibility to the general public about environmental sciences, local people's daily lives and concerns.

Why: The upgraded sets of pictures are then given to the stakeholders (through the exhibitions or booklets) as take home messages representing the adapted vision of the landscape seen by a camera with eyes from the scientists, photographer and stakeholders. This becomes a boundary object that can be used in negotiation and to trigger further thought processes. We observed that these photographs, sometimes together with the game sheet for the stakeholders having participated to game sessions, have been pinned on the house walls, thus entering the household and more importantly the mental models and decision making. These multidisciplinary take home messages take a new path towards the understanding of landscapes, the interactions of the various stakeholders in the landscape, and also the way they will explain omitted visions in further iterations of the process. It also helps local actors to realize they have something important in the environment and a way of life that they should treasure and protect. these, i.e. field and feedback, for as long as the participatory project lasts. We should then eventually approach saturation-where no new topic emerges from the photography nor from the interviews. We will then enter project closure.

The importance of having an external person to the place, traditions, and culture comes from their ability to see things that the actors may be too involved to notice. The iteration aspect of the method ensures that the local actors can question their views by confronting them with the ones of the photographer and researchers. Although it is unsure whether local farmers will change their habits, at least they might develop a different view about them. The pictures in this sense act like the games. Then the 'western eye' is completed by their views and it stops being entirely external. In addition, the final artistic work and the exhibitions were achieved in collaboration with a Malagasy photographer from Antananarivo, bringing in yet another point of view, in this case one that shares the same culture with the actors but comes from a different location. During exhibitions in the Ambatondrazaka region research sites, school children (primary and secondary levels) were invited to visit and interact with the photo- graphers and the researchers. They played games and exchanged views about the photographic representation of the Alaotra landscape and activities that are theirs. One of the positive outcomes was that many expressed that this event had helped them realize the importance of their environment and culture. Some even discovered aspects of their environment they were unaware of, such as the diversity of fishing techniques.

\section{EPILOGUE}

Complexity is overwhelming. Embracing it requires being able to think on the multiple causal links and feedback loops between all the different components of the system that interact, and allow for change in common understanding. It requires time and the possibility to devote attention to problems beyond the immediate needs or the day-to-day activities. It needs seeing things we do not normally pay attention to. It calls for a space of freedom where the multiple aspects of the problems at stake can be approached in a non-threatening environment. Photography allows us to create a common visual representation of the world as seen from multiple eyes. The models (games) we co-design give depth 

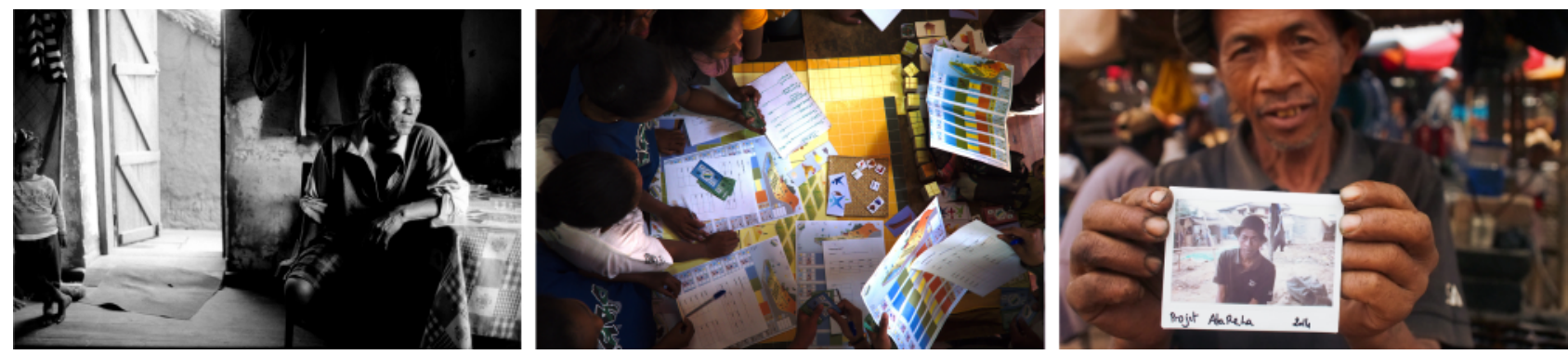

Figure 3. Three types of photography: analogies, digitals, instants. [left] A black and white picture of the daily life of the Alaotra region, with a strong artistic parti-prix. [middle] A documentation of a role-playing game session based on land conservation, linking NGO staff with local government, in a NGO headquarter. [right] Use of instant photography, leaving some pictures to the people who accepted to enter discussions and share their time and knowledge.
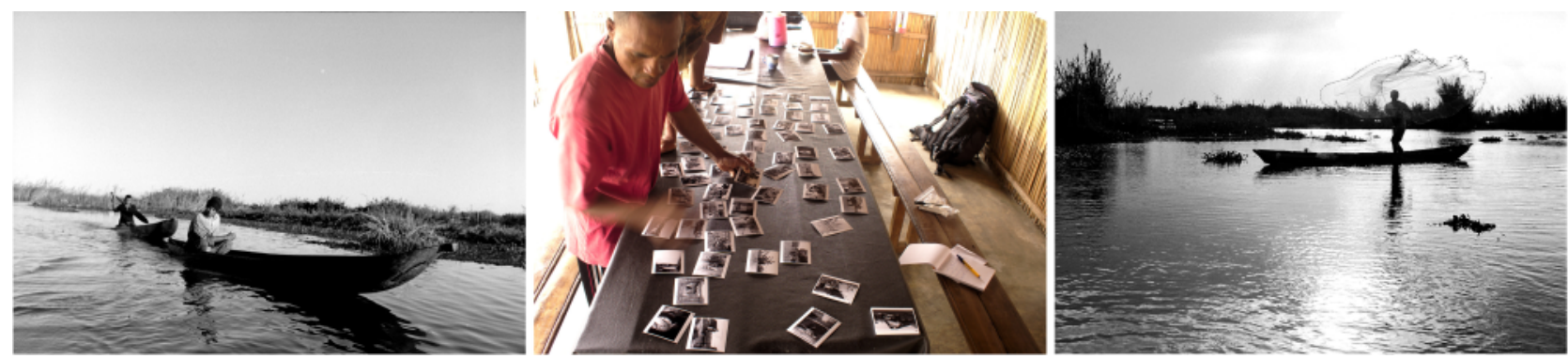

Figure 4. Complementing the social-ecological landscape through photography. [left] From the first visit, some fishermen paddle back to the Andreba harbor at dawn, meeting with fish collectors. [middle] a fisherman during the iteration workshop; he stated that he would like to see fishermen actually in the act of fishing as there are many different techniques used on the Alaotra lake. [right] Following the fisherman's feedback, a picture of one of the fishing techniques.

to these images, allowing to define the linkages and interactions between the different elements of a social-ecological system. The game sessions make participants more aware that they are part of a bigger system by showing them physical zones (ecosystems) as well as the diversity of stakeholders. The impact of games is less in the actual outcome of changes in ecosystems, but rather in the empowerment of the people. It allows them to gain consciousness of the decision making process. People can choose amongst several options with the awareness that their decisions act upon two dimensions of the social-ecological system, which are inherently linked and interconnected, their livelihood situation, and the physical system. The games we play let us tell narratives about how things work and how they could work. Together, researchers, villagers, conservationists, decision makers and photographer are engaged in an iterative dialogue of narratives and visuals, and thus are complementing but also exploring possible futures of their social-ecological landscapes to make better decisions today. Every decision matters and has consequences 'further down' in time and space, even the decision to do nothing. One cannot change the world by taking pictures and playing games, but the way people think can be changed by showing them different points of views, and then "the ball is in their hands".

\section{ACKNOWLEDGMENTS}

We acknowledge the continuous support received by the local authorities from Ambatondrazaka, all the participants to this research for playing and discussing with us to share their views and visions to gain a better understanding of the Alaotra system. We also thank the anonymous reviewers and editors of the journal Madagascar Conservation \& Development for helpful comments and support. This research was funded by the Swiss Programme for Research on Global Issues for Development under the research grant IZ01Z0_146852 as part of the AlaReLa Alaotra Resilience Landscape project.

\section{REFERENCES}

Butchart, S. H. M., Walpole, M., Collen, B., van Strien, A., Scharlemann, J. P. W. et al. 2010. Global biodiversity: indicators of recent declines. Science 328, 5982: 1164-1168. (doi:10.1126/science.1187512)

Cardinale, B. J., Duffy, J. E., Gonzalez, A., Hooper, D. U., Perrings, C. et al. 2012. Biodiversity loss and its impact on humanity. Nature 486: 59-67. (doi:10.1038/nature11148)

Cole, J. 1997. Sacrifice, narratives and experience in east Madagascar. Journal of Religion in Africa 27, 4: 401-425.

Copsey, J. A., Jones, J. P. G., Andrianandrasana, H., Rajaonarison, L. $\mathrm{H}$. and Fa, J. E. 2009a. Burning to fish: local explanations for wetland burning in Lac Alaotra, Madagascar. Oryx 43, 3: 403-406. (doi:10.1017/S0030605309000520)

Copsey, J. A., Rajaonarison, L. H., Randriamihamina, R. and Rakotoniaina, L. J. 2009b. Voices from the marsh: Livelihood concerns of fishers and rice cultivators in the Alaotra wetland. Madagascar Conservation \& Development 4, 1: 25-30. (doi:10.4314/mcd.v4i1.44008)

Coser, L. A. 1992. The revival of the sociology of culture: the case of collective memory. Sociological Forum 7, 2: 365-373. (doi:10.1007/BF01125050)

Deguignet, M., Juffe-Bignoli, D., Harrison, J., Macsharry, B., Burgess, N. D. and Kingston, N. 2014. 2014 United Nations list of Protected Areas. UNEP-WCMC, Cambridge, UK.

Etienne, M., Bousquet, F., Le Page, C. and Trébuil, G. 2014. Transferring the ComMod approach. In: Companion Modelling. M. Etienne (ed.), pp 291-309. Springer, The Netherlands.

Ganzhorn J. U., Lowry II, P. P., Schatz, G. E. and Sommer, S. 2001. The biodiversity of Madagascar: one of the world's hottest hotspots on its way out. Oryx 35, 4: 346-348. (doi:10.1046/j.1365-3008.2001.00201.x)

Garcia, C., Dray, A. and Waeber, P. 2016. Learning begins when the game is over: Using games to embrace complexity in natural resources management. GAIA - Ecological Perspectives for Science and Society 25, 4: 289-291. (doi:10.14512/gaia.25.4.13) 
García-Barrios, L., García-Barrios, R., Cruz-Morales, J. and Smith, J. A. 2015. When death approaches: reverting or exploiting emergent inequity in a complex land-use table-board game. Ecology and Society 20, 2: 13. (doi:10.5751/ES-07372-200213)

Golden, C. D. 2009. Bushmeat hunting and use in the Makira Forest, north-eastern Madagascar: a conservation and livelihoods issue. Oryx 43, 3: 386-392. (doi:10.1017/S003060530900013)

Grindle, M. S. 2004. Good enough governance: poverty reduction and reform in developing countries. Governance 17, 4: 525-548. (doi:10.1111/j.0952-1895.2004.00256.x)

Guillou, M. and Matheron, G. 2014. Will there be enough land? In: The World's Challenge. M. Guillou and G. Matheron (eds.), pp 115-140. Springer, The Netherlands.

Innes, J. L. 2010. Madagascar rosewood, illegal logging and the tropical timber trade. Madagascar Conservation \& Development 5, 1: 6-10. (doi:10.4314/mcd.v5i1.57335)

Jenkins, R. K. B., Keane, A., Rakotoarivelo, A. R., Rakotomboavonjy, V., Randrianandrianina, F. H. and Razafimanahaka, H. J. 2011. Analysis of patterns of bushmeat consumption reveals extensive exploitation of protected species in eastern Madagascar. Plos ONE 6, 12: e27570. (doi:10.1371/journal.pone.0027570)

Kates, R. W., Clark, W. C., Corell, R., Hall, J. M., Jaeger, C. C. et al. 2001. Sustainability science. Science 292, 5517: 641-642. (doi:10.1126/science.1059386)

Kolstad, I. and Wiig, A. 2009. Is transparency the key to reducing corruption in resource-rich countries? World Development 37, 3: 521-532. (doi:10.1016/j.worlddev.2008.07.002)

Lang, D. J., Wiek, A., Bergmann, M., Stauffacher, M., Martens, P. et al. 2012. Transdisciplinary research in sustainability science: practice, principles, and challenges. Sustainability Science 7, S1: 25-43. (doi:10.1007/s11625-011-0149-x)

Le Page, C., Dray, A., Perez, P. and Garcia, C. 2016. Exploring how knowledge and communication influence natural resources management with ReHab. Simulation and Gaming. 47, 2: 257-284. (doi:10.1177/1046878116632900)

Max-Neef, M. A. 2005. Foundations of transdisciplinarity. Ecological Economics 53, 1: 5-16. (doi:10.1016/j.ecolecon.2005.01.014)

Mezirow, J. 1997. Transformative learning: Theory to practice. New Directions For Adult \& Continuing Education 74: 5-12. (doi:10.1002/ace.7401)

Ostrom, E., 2009. A general framework for analyzing sustainability of social-ecological systems. Science 325, 5939: 419-422. (doi:10.1126/science.1172133)

Pett, T. J., Shwartz, A., Irvine, K. N., Dallimer, M. and Davies, Z. G. 2016. Unpacking the people-biodiversity paradox: a conceptual framework. Bioscience. 66, 7: 576-583. (doi:10.1093/biosci/biw036)

Ralainasolo, F. B. 2004. Action des effets anthropiques sur la dynamique de la population de Hapalemur griseus alaotrensis ou "Bandro" dans son habitat naturel. Lemur News 9: 32-35.

Ralainasolo, F. B., Waeber, P. O., Ratsimbazafy, J., Durbin, J. and Lewis, R. 2006. The Alaotra gentle lemur: Population estimation and subsequent implications. Madagascar Conservation \& Development 1, 1: 9-10. (doi:10.4314/mcd.v1i1.44044)

Randriamalala, H. and Liu, Z. 2010. Rosewood of Madagascar: Between democracy and conservation. Madagascar Conservation \& Development $5,1: 11-22$ (doi:10.4314/mcd.v5i1.57336)

Randrianja, S. 2012. Love me tender-Transition vers où ? Madagascar Conservation \& Development 7, 1: 9-16. (doi:10.4314/mcd.v7i1.3)
Ratsimbazafy, J. H., Ralainasolo, F. B., Rendigs, A., MantillaContreras, J., Andrianandrasana, H. et al. 2013. Gone in a puff of smoke? Hapalemur alaotrensis at great risk of extinction. Lemur News 17:14-18.

Reibelt, L. M., Moser, G., Dray, A., Ralainasolo, I. H., Chamagne, J., et al. 2017 (In press). Tool development to understand rural resource users' land use and impacts on land type changes in Madagascar. Madagascar Conservation \& Development.

Waeber, P. O. and Wilmé, L. 2013. Madagascar rich and intransparent. Madagascar Conservation \& Development 8, 2: 52-54. (doi:10.4314/mcd.v8i2.1)

Waeber, P. O., Wilmé, L., Ramamonjisoa, B., Garcia, C., Rakotomalala, D. et al. 2015. Dry forests in Madagascar: neglected and under pressure. International Forestry Review 17, S2: 127-148. (doi:10.1505/146554815815834822)

Waeber, P. O., Reibelt, L. M., Randriamalala, I. H., Moser, G., Raveloarimalala, L. M. et al. 2017a (In press). Local awareness and perceptions: consequences for conservation of marsh habitat at Lake Alaotra for one of the world's rarest lemurs. Oryx. (doi:10.1017/S0030605316001198)

Waeber, P. O., Ratsimbazafy, J. H., Andrianandrasana, H., Ralainasolo, F. B. and Nievergelt, C. M. 2017b (In press). Hapalemur alaotrensis, a conservation case study from the swamps of Alaotra, Madagascar. In: Primates in Flooded Habitats: Ecology and Conservation. A. Barnett, I. Matsuda and K. Nowak (eds.). Cambridge University Press, Cambridge.

Wilmé, L., Goodman, S. M. and Ganzhorn, J. U. 2006. Biogeographic evolution of Madagascar's microendemic biota. Science 312, 5776: 1063-1065. (doi:10.1126/science.1122806)

Wilmé, L., Ravokatra, M., Dolch, R., Schuurman, D., Mathieu, E. et al. 2012. Toponyms for centers of endemism in Madagascar. Madagascar Conservation \& Development 7, 1: 30-40. (doi:10.4314/mcd.v7i1.6)

Worm, B., Barbier, E. B., Beaumont, N., Duffy, J. E., Folke, C. et al. 2006. Impacts of biodiversity loss on ocean ecosystem services. Science 314, 5800: 787-790. (doi:10.1126/science.1132294) 